\title{
Morphological and Elemental Investigations on Co-Fe-B-O Thin Films Deposited by Pulsed Laser Deposition for Alkaline Water Oxidation: Charge Exchange Efficiency as the Prevailing Factor in Comparison with the Adsorption Process
}

\author{
Y. Popat ${ }^{1} \cdot$ M. Orlandi ${ }^{1} \cdot$ S. Gupta ${ }^{2} \cdot$ N. Bazzanella ${ }^{1} \cdot$ S. Pillai ${ }^{3} \cdot$ M. K. Patel ${ }^{2} \cdot$ A. Miotello $^{1} \cdot$ N. Patel $^{4}$
}

Received: 17 December 2020 / Accepted: 25 April 2021 / Published online: 8 May 2021

(c) The Author(s) 2021

\begin{abstract}
Mixed transition-metals oxide electrocatalysts have shown huge potential for electrochemical water oxidation due to their earth abundance, low cost and excellent electrocatalytic activity. Here we present $\mathrm{Co}-\mathrm{Fe}-\mathrm{B}-\mathrm{O}$ coatings as oxygen evolution catalyst synthesized by Pulsed Laser Deposition (PLD) which provided flexibility to investigate the effect of morphology and structural transformation on the catalytic activity. As an unusual behaviour, nanomorphology of 3D-urchin-like particles assembled with crystallized $\mathrm{CoFe}_{2} \mathrm{O}_{4}$ nanowires, acquiring high surface area, displayed inferior performance as compared to core-shell particles with partially crystalline shell containing boron. The best electrochemical activity towards water oxidation in alkaline medium with an overpotential of $315 \mathrm{mV}$ at $10 \mathrm{~mA} / \mathrm{cm}^{2}$ along with a Tafel slope of $31.5 \mathrm{mV} /$ dec was recorded with core-shell particle morphology. Systematic comparison with control samples highlighted the role of all the elements, with Co being the active element, boron prevents the complete oxidation of $\mathrm{Co}$ to form $\mathrm{Co}^{3+}$ active species $(\mathrm{CoOOH})$, while $\mathrm{Fe}$ assists in reducing $\mathrm{Co}^{3+}$ to $\mathrm{Co}^{2+}$ so that these species are regenerated in the successive cycles. Thorough observation of results also indicates that the activity of the active sites play a dominating role in determining the performance of the electrocatalyst over the number of adsorption sites. The synthesized $\mathrm{Co}-\mathrm{Fe}-\mathrm{B}-\mathrm{O}$ coatings displayed good stability and recyclability thereby showcasing potential for industrial applications.
\end{abstract}

\section{Graphic Abstract}
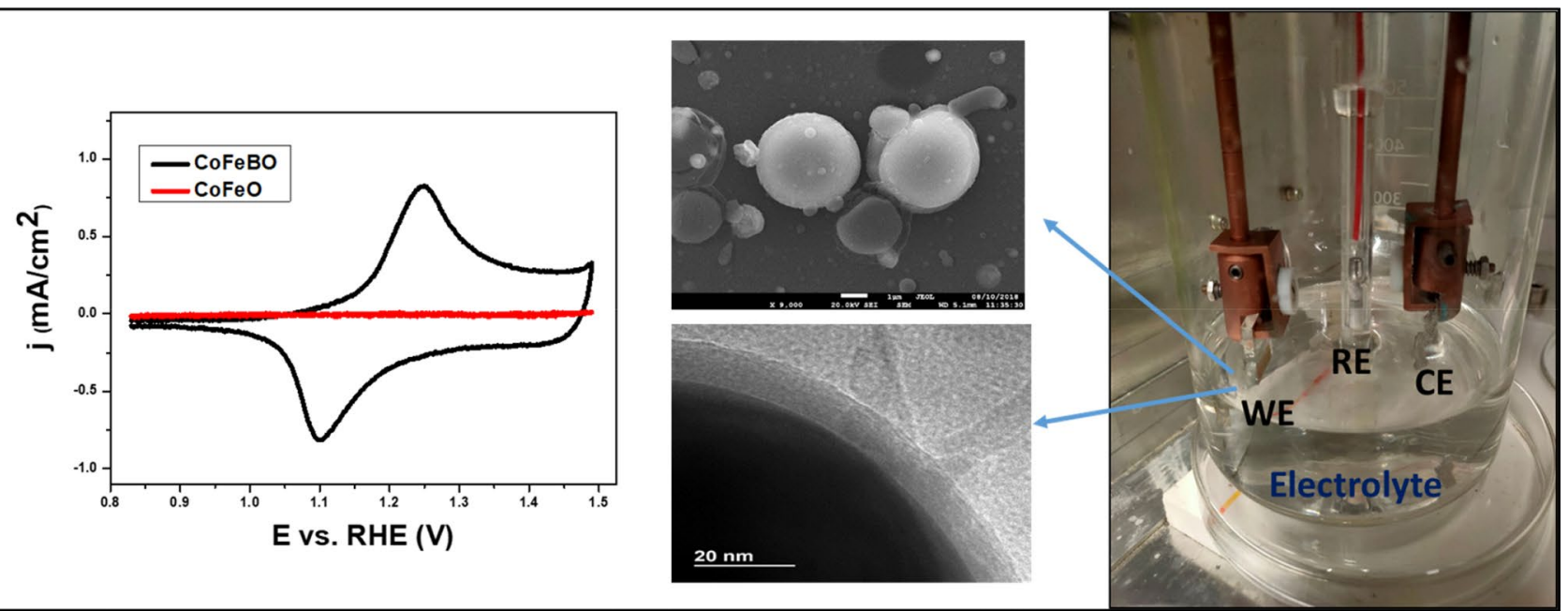

Keywords Water oxidation $\cdot$ Electrocatalysis $\cdot$ Hierarchical $\cdot$ Nanostructured $\cdot$ Coatings

Extended author information available on the last page of the article 


\section{Introduction}

The rapid industrialization coupled with large increase of population forces us to think seriously and urgently about the problem of energy and related sources of the planet. Hence, it is important to look for alternate renewable energy carriers like hydrogen to sustain the current as well as future energy needs. Currently, hydrogen production occurs mainly through steam reforming of natural gas and coal gasification, leading to high emission of greenhouse gases along with its fossil fuel dependence [1]. Electrochemical water splitting has been considered as one of the promising techniques for sustainable production of hydrogen $\left(\mathrm{H}_{2}\right)$ and oxygen $\left(\mathrm{O}_{2}\right)$ owing to simple nature of the process along with no harmful gas emission and high conversion efficiency [2-6]. Oxygen Evolution Reaction (OER), one of the two half-reactions in watersplitting, is more complex and usually requires a large overpotential to overcome the kinetic barrier associated with the exchange of four electrons and thus shows very slow kinetics [7]. Hence, electrocatalysts are required in this process to reduce the overpotential and improve the efficiency of the process. Metal oxides are generally more stable for water oxidation reactions compared to metals due to their resistance in getting oxidized even further [8]. Iridium oxide $\left(\mathrm{IrO}_{2}\right)$ and ruthenium oxide $\left(\mathrm{RuO}_{2}\right)$ catalysts are reported to be some of the best OER electrocatalysts, owing to their performance and stability in PEM electrolyzers [9]. However, they belong to the rare inert group of catalysts and are scarcely available on earth [10]. These catalysts are also comparatively less stable in alkaline medium, limiting their use in alkaline water electrolyzers. Hence, efforts have been made to synthesize electrocatalysts which are abundant and made up of cheap scalable materials like Ni, Fe and Co [11-14]. Transition metal oxides of $\mathrm{Fe}$ and $\mathrm{Co}$ are extensively studied for photocatalytic $[15,16]$ and electrocatalytic $[17,18]$ water oxidation respectively, due to their earth abundance, low cost and stability in alkaline solutions. $\mathrm{Fe}_{2} \mathrm{O}_{3}$ and its composites have been investigated as photoanodes demonstrating promising results in photo-electrochemical water splitting [19-24]. On the other hand, $\mathrm{Co}_{3} \mathrm{O}_{4}$ and $\mathrm{Co}$ oxide nanostructures have exhibited efficient activity as Oxygen Evolution Catalysts (OECs) in electrochemical water splitting $[10,25,26]$ Cobalt oxide catalysts are generally quite active for OER in the alkaline medium [27-29]. Owing to the advancements in the electrochemical studies on cobalt and iron based oxides, research progressed towards electrochemical water splitting using mixed oxide OEC's of cobalt and iron [30-32]. The electrocatalysts, however, were synthesized in the powder form thus limiting their industrial application. Thus, it is essential to explore the possibility of using mixed metal oxide catalyst in form of coatings or films with nanostructured morphology.

Pulsed Laser Deposition (PLD) is an effective technique for fabrication of catalysts coatings due to the possibility to tune various deposition parameters like ambient gas and related pressure, energy fluence, laser wavelength, etc. to obtain distinct nanostructured morphologies on several kinds of substrates [33-35]. Various metal oxide catalysts have been synthesized by PLD as water oxidation catalyst (WOC) [21, 36, 37]. 3D hierarchical nanostructured coatings of $\mathrm{Co}_{3} \mathrm{O}_{4}$ and iron oxides synthesized with boron by using boric acid as a source of boron in the initial target mixture, displayed excellent photocatalytic [38, 39] performance. Similarly prepared $\mathrm{CoFe}_{2} \mathrm{O}_{4} / \mathrm{CoO}$ hierarchical-type nanostructured coating synthesized with boron exhibited excellent photocatalytic activity towards degradation of methylene blue dye [40]. Boron was also introduced in synthesis of mixed metal oxide/boride electrocatalysts towards OER displaying enhanced electrochemical performance [41, 42].

In view of the enhanced photocatalytic and electrocatalytic performance seen by inclusion of boron, primarily in the outer shell of the nanoparticles, it would be interesting to perform in-depth study of its effect on the electrochemical performance of the films. In this paper, we synthesize $\mathrm{Co}-\mathrm{Fe}-\mathrm{B}-\mathrm{O}$ coatings on Fluorine Tin Oxide (FTO) substrates as a WOC for OER. The coatings were synthesized by PLD with targets comprising of a mixture of metallic $\mathrm{Fe}, \mathrm{Co}$ and boric acid $\left(\mathrm{H}_{3} \mathrm{BO}_{3}\right)$. The synthesis protocol is adopted from our past work [40]. A systematic morphological and compositional characterization was carried out in order to investigate the role of number of active sites and the activity of each site on the electrochemical performance of the electrocatalyst. The mixed metal oxide coating exhibited good electrocatalytic activity with an overpotential of $315 \mathrm{mV}$ at $10 \mathrm{~mA} / \mathrm{cm}^{2}$ current density along with a low Tafel slope of $31.5 \mathrm{mV} / \mathrm{dec}$. The coatings also displayed high stability and recyclability in alkaline medium with almost no deterioration. The mechanistic role of all the elements in the coating was studied in detail and discussed.

\section{Experimental}

\subsection{Synthesis}

A mixture of Fe metallic, Co metallic and boric acid $\left(\mathrm{H}_{3} \mathrm{BO}_{3}\right)$ powders mixed in molar ratios of 1:1:1 was compressed in the form of a disc to be used as a target for the deposition of $\mathrm{CoFeOx}$ coatings by PLD. A KrF excimer laser (Lambda Physik) with an operating wavelength of $248 \mathrm{~nm}$, pulse duration of $25 \mathrm{~ns}$, and repetition rate of 20 $\mathrm{Hz}$ was used for deposition. The fluence of the laser was always maintained at $3 \mathrm{~J} / \mathrm{cm}^{2}$. Details of PLD apparatus and 
the mechanisms involved in the laser matter interactions are presented in our past reports [43, 44]. Before the depositions, the PLD chamber was evacuated up to a base pressure of $10^{-6}$ mbar. Deposition of the coatings were carried out in an Argon atmosphere at a pressure of $1.5 \times 10^{-2}$ mbar. The target to substrate distance was fixed at $4.5 \mathrm{~cm}$ with the substrate positioned parallel to the target. The coatings were deposited on FTO coated glass, borosilicate glass and Silicon wafer at room temperature and the number of pulses used for deposition were 10,000. Following the depositions, thermal annealing were carried out in air at $200{ }^{\circ} \mathrm{C}, 400{ }^{\circ} \mathrm{C}$ and $600{ }^{\circ} \mathrm{C}$ for $5 \mathrm{~h}$ with a heating rate of $5^{\circ} \mathrm{C} / \mathrm{min}$.

\subsection{Characterization}

Scanning Electron Microscope (SEM-FEG, JSM 7001F, JEOL) operating at $20 \mathrm{keV}$ electron beam energy fitted with energy dispersive spectroscopy analysis (EDS, INCA PentaFET-x3) tested the surface morphologies of all samples prepared by PLD. A JEOL 2100F Cs-corrected analytical FEG TEM with an accelerating voltage of $200 \mathrm{kV}$ fitted with an energy-dispersive $\mathrm{X}$-ray spectrometer (EDAX) performed the transmission electron microscopy (TEM) and high resolution TEM (HR-TEM) analyses. Images were analysed using Gatan's Optical Micrograph program. Holey-carbon film copper grids (300 mesh) were used as substrates to prepare samples for TEM analysis. Using X-Ray Diffractometer (XRD, Rigaku Miniflex) with $\mathrm{Cu} \mathrm{K}_{\alpha}$ radiation $(\lambda=1.5414$ $\AA$ ) in $2 \theta-\theta$ configuration, step size of $0.05^{\circ}$ and a scan rate of $1 \% \mathrm{~min}$, structural characterization of the coatings were carried out. PHI 5000 Versa II instrument equipped with a monochromatic $\mathrm{Al} \mathrm{K}_{\alpha}(1486.6 \mathrm{eV}) \mathrm{X}$-ray source and a hemispherical analyser performed X-ray Photoelectron Spectroscopy (XPS) to analyse the surface composition and chemical states of each element present in the sample analysed. To perform the XPS study, adequate electrical charge compensation was required.

\subsection{Electrochemical Measurements}

Electrochemical measurements were performed using a Gamry potentiostat/Galvanostat/ZRA interface 1000 in a three-electrode cell composed of Saturated Calomel Electrode (SCE, $0.244 \mathrm{~V}$ vs. Standard Hydrogen Electrode) as reference, Pt mesh as counter electrode and $1 \mathrm{M} \mathrm{KOH}$ solution (pH 14) as electrolyte. Catalysts deposited on FTO glass substrates $\left(1 \mathrm{~cm}^{2}\right)$ were used as working electrodes. Initially, Cyclic Voltammetry (CV) scans were performed on the samples to remove the impurities and stabilize the current. Linear Sweep Voltammetry (LSV) was carried out with iR compensation. The LSV measurements were done at a scan rate of $10 \mathrm{mV} / \mathrm{s}$ while the $\mathrm{CV}$ measurements were done at a scan rate of $100 \mathrm{mV} / \mathrm{s}$. Commercial $\mathrm{RuO}_{2}$ nanoparticles were used for LSV measurements. Finally, Chronoamperometry (CA) measurements were performed on the samples to check the stability of the catalysts for water oxidation reactions. Electrochemical impedance spectroscopy (EIS) was performed in the frequency range of $2 \mathrm{MHz}$ to $10 \mathrm{~Hz}$ with an input sinusoidal wave of amplitude $50 \mathrm{mV}$, at $0.5 \mathrm{~V}$ vs open circuit potential (OCP). EIS data was fitted using Echem Analyst software from Gamry to obtain the equivalent electrical circuits. Determination of the electrochemical surface area (ESA) was carried out by calculating the double layer capacitance $\left(\mathrm{C}_{\mathrm{DL}}\right)$ from $\mathrm{CV}$ scans in the non-Ohmic potential region of $0.725-1.025 \mathrm{~V}$ (vs RHE), at increasing scan rates. The graph of difference in cathodic and anodic current densities at $0.875 \mathrm{~V}$ was plotted against the respective scan rates to determine the value of $\mathrm{C}_{\mathrm{DL}}$.

\section{Results and Discussions}

All the previous works on $\mathrm{Co}-\mathrm{Fe}-\mathrm{B}-\mathrm{O}$ catalysts have been reported in the powder form [41, 42]. Thus in order to explore the viability on industrial scale, $\mathrm{Co}-\mathrm{Fe}-\mathrm{B}-\mathrm{O}$ catalyst coating was deposited by PLD on FTO electrodes. In view of studying the influence of morphology and crystallinity of $\mathrm{Co}-\mathrm{Fe}-\mathrm{B}-\mathrm{O}$ catalyst on OER performance, the mixed metal oxide coatings were annealed at three different temperatures $\left(200{ }^{\circ} \mathrm{C}, 400{ }^{\circ} \mathrm{C}\right.$ and $\left.600{ }^{\circ} \mathrm{C}\right)$ in air. As-deposited (AD) as well as annealed coatings (designated as AN200, AN400 and AN600) were investigated by electron microscopy (SEM and TEM) and diffraction techniques (XRD) to get insights on the surface morphologies and the structural changes that occur upon annealing. The AD coating (Fig. 1a) shows particle like morphology with dispersed particle size distribution from tens of nanometer to a few micrometers. This kind of morphology is expected owing to the phase explosion process which occurs when the target surface comes close to the thermodynamic critical temperature upon irradiating with high laser fluence. Moreover, these particles are in core-shell structure as observed at higher magnification and the elemental contrast image suggests that the core is made up of heavy elements like $\mathrm{Fe}$ and $\mathrm{Co}$ while the shell comprises of lighter elements, mainly boron and oxygen along with metals. AD coatings have the core primarily in elemental phase with oxidation coming into effect upon annealing. The exact reason for formation of such morphology with distinct composition is explained in detail in our past work [39]. The core-shell morphology of $\mathrm{Co}-\mathrm{Fe}-\mathrm{B}-\mathrm{O}$ coatings at annealed temperatures comprises of a mix of elemental phases $(\mathrm{Co}, \mathrm{Fe})$, single oxide phases ( $\mathrm{CoOx}, \mathrm{FeOx}, \mathrm{FeBO}_{3}, \mathrm{~B}_{2} \mathrm{O}_{3}$ etc.) and mixed metal oxide (MMO) phases like $\mathrm{CoFe}_{2} \mathrm{O}_{4}$. This happens because upon annealing, the shell of the coatings get oxidised first with the core getting exposed later. As a result, the core contains the 
Fig. 1 a-c SEM, d-f TEM, g-i HRTEM and $\mathbf{j}$ XRD pattern for AD, AN400 and AN600 coatings
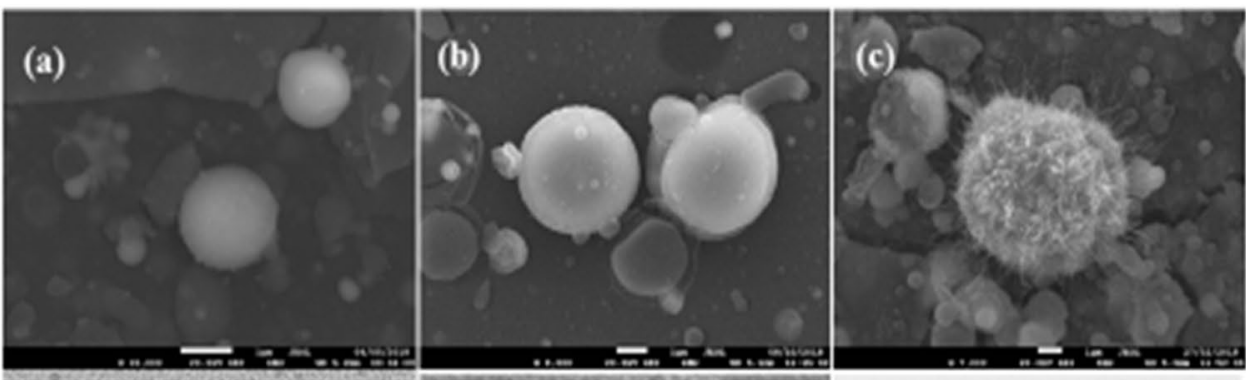

(d)

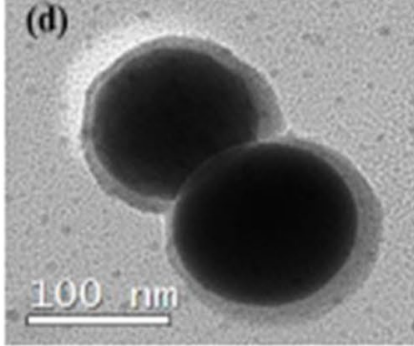

(e)

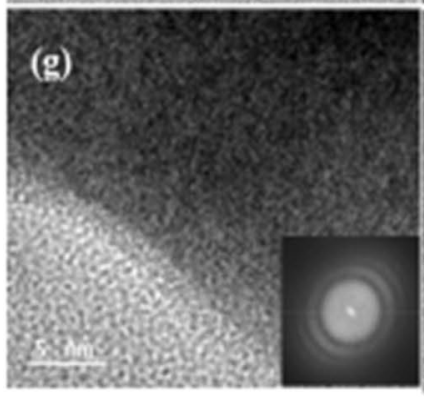

$20 \mathrm{~nm}$

(i)

(f)

$10 \mathrm{~nm}$

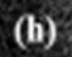

(b)

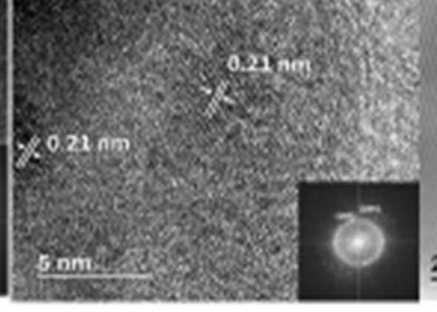

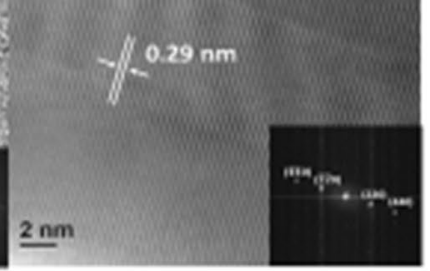

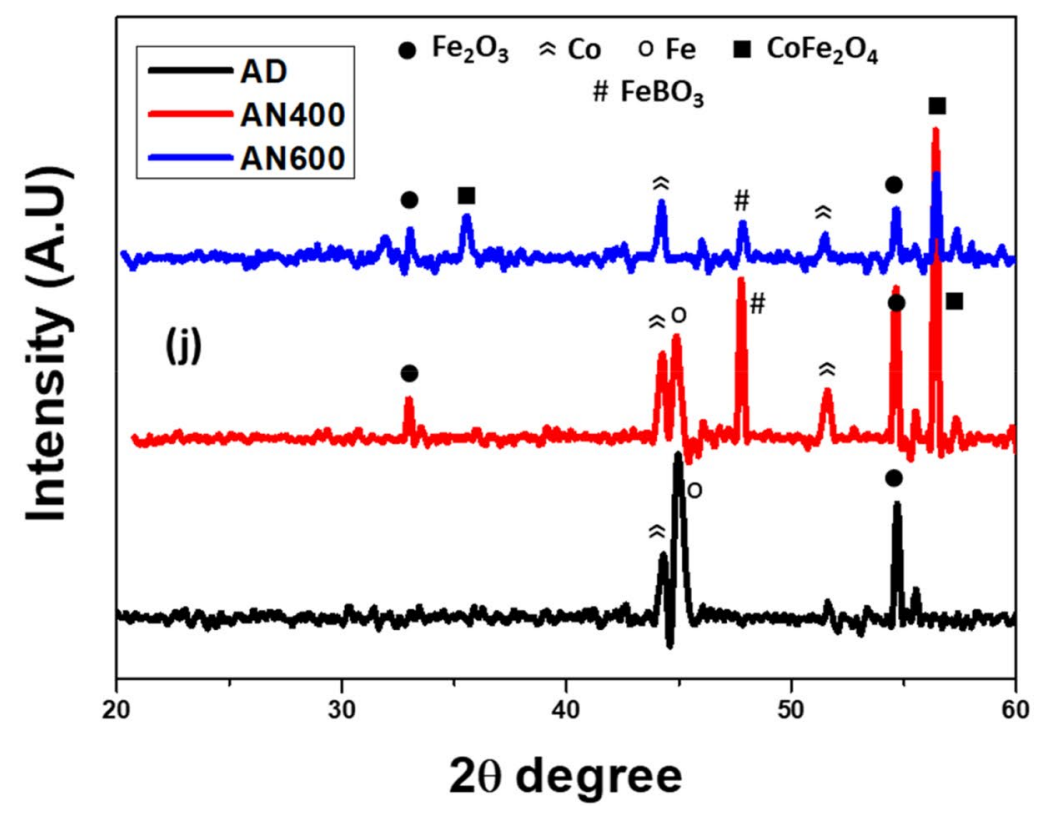

metals in the elemental phase even after annealing at higher temperatures. No major variation in the morphology was detected upon annealing at $200{ }^{\circ} \mathrm{C}$ and $400{ }^{\circ} \mathrm{C}$ except the core-shell structure is more prominently visible (Fig. 1b). The sharp contrast between core and shell is also visible in TEM images with the shell thickness of about $8-10 \mathrm{~nm}$ depending on particle size (Fig. 1d, e). This shell is completely amorphous in the case of AD and AN200 coatings (Fig. 1g). In AN400, partial crystallization in the shell with lattice fringes having $\mathrm{d}$-spacing of $0.21 \mathrm{~nm}$ ascribed to (004) 
plane of $\mathrm{CoFe}_{2} \mathrm{O}_{4}$, is clearly visible in the HRTEM image (Fig. 1h). Diffuse ring along with bright spot indexed to $\mathrm{CoFe}_{2} \mathrm{O}_{4}$ phase was recorded in Fast Fourier Transform (FFT) pattern (inset of Fig. 1h), thus suggesting the formation of nano-crystalline phase with nano-size domains separated by grain boundaries. In AN600, the shell disintegrates to form nanowires (NWs) on the surface of the particles, thus a complete transformation of morphology occurs from spherical particulates to urchin-like hierarchical structures with vertically grown NWs from surface of the particulates (Fig. 1c). The length and diameter of the NWs vary from 0.5 to $1 \mu \mathrm{m}$ and $10-30 \mathrm{~nm}$ (Fig. 1f), respectively. The detailed mechanism behind the formation of this hierarchical nanostructured coating at elevated temperatures is reported in our previous work [38, 39]. Figure 1i shows the HRTEM image of a representative NW from the hierarchical urchin like structures of AN600. The surface of the NW shows a d-spacing of $0.29 \mathrm{~nm}$ ascribed to (220) plane of $\mathrm{CoFe}_{2} \mathrm{O}_{4}$ phase (JCPDS file: 22-1086) phase. The bright distinct spot in FFT (inset of Fig. 1i) of this NW can be perfectly indexed to $\mathrm{CoFe}_{2} \mathrm{O}_{4}$ phase. On the basis of above results, it is clear that the core-shell morphology is maintained till $400{ }^{\circ} \mathrm{C}$ with partially crystallized shell of $\mathrm{CoFe}_{2} \mathrm{O}_{4}$ phase. However, further increase in temperature leads to entire change in morphology to urchin-like hierarchical nanostructure with crystalline NWs of $\mathrm{CoFe}_{2} \mathrm{O}_{4}$ phase.

XRD pattern was acquired (Fig. 1j) to mainly investigate the crystallinity of the particulates on the coating surface. For AD coating, the peaks indicate the presence of metallic $\mathrm{Co}$ and $\mathrm{Fe}$ in the coating along with the $\alpha-\mathrm{Fe}_{2} \mathrm{O}_{3}$ phase (JCPDS 33-0664). In AN400, additional peaks corresponding to $\mathrm{CoFe}_{2} \mathrm{O}_{4}$ (JCPDS 22-1086) and $\mathrm{FeBO}_{3}$ [45] phases are observed. On further annealing at $600{ }^{\circ} \mathrm{C}$, complete crystallization occurs, with $\mathrm{CoFe}_{2} \mathrm{O}_{4}, \mathrm{FeBO}_{3}$ and $\alpha-\mathrm{Fe}_{2} \mathrm{O}_{3}$ phases. The presence of metallic $\mathrm{Fe}$ and $\mathrm{Co}$ in the coatings cannot be ruled out due to the metallic core of the particles.

The elemental survey scan of XPS detects elements such as $\mathrm{Co}, \mathrm{Fe}, \mathrm{B}$ and $\mathrm{O}$ along with residual carbon for both, $\mathrm{AD}$ as well as annealed samples. Focused scan of $\mathrm{Fe}_{2 \mathrm{p}}$ level shows existence of two distinct peaks attributed to $2 \mathrm{p}_{3 / 2}$ and $2 \mathrm{p}_{1 / 2}$ levels for all the coatings (Fig. 2). The deconvolution of $2 \mathrm{p}_{3 / 2}$ level for $\mathrm{AD}$ coating exhibits two peaks centered at $711.4 \mathrm{eV}$ and $712.8 \mathrm{eV}$ corresponding to $\mathrm{Fe}^{3+}$ state in $\mathrm{FeOOH}$ and $\mathrm{FeBO}_{3}$ respectively $[46,47]$. The satellite peak at $718 \mathrm{eV}$ also provides evidence of presence of only $\mathrm{Fe}^{3+}$ state. Thus $\mathrm{Fe}$ is in higher oxidation state which is in agreement with previous report on CoFeBO powder [41]. In AN200, the lower BE peak is shifted to $710.6 \mathrm{eV}$ assigned to $\mathrm{Fe}^{3+}$ state in $\mathrm{CoFe}_{2} \mathrm{O}_{4}$ phase thus suggesting the initiation of formation of $\mathrm{CoFe}_{2} \mathrm{O}_{4}$ phase at this temperature [48]. Further increase in temperature at $400{ }^{\circ} \mathrm{C}$ causes an increase in the intensity of this peak. The existence of peak at $712.8 \mathrm{eV}$ due to $\mathrm{FeBO}_{3}$ is maintained at both these temperatures. However, in AN600, the peak at $712.8 \mathrm{eV}$ drastically increases as compared to lower B.E peak. This shows that at $600{ }^{\circ} \mathrm{C}$, the $\mathrm{FeBO}_{3}$ and $\mathrm{CoFe}_{2} \mathrm{O}_{4}$ phases coexist at the surface. In Co2p XPS spectra of the AD sample, the broad peak due to $2 \mathrm{p}_{3 / 2}$ level can be deconvoluted into two peaks centered at $782.0 \mathrm{eV}$ and $786.0 \mathrm{eV}$ with the sharp peak assigned to $\mathrm{Co}^{2+}$ in $\mathrm{Co}(\mathrm{OH})_{2}$ state [49] while the broad peak is the satellite peak of $\mathrm{Co}^{2+}$ species. Upon annealing at $200{ }^{\circ} \mathrm{C}$, an additional peak at $780.8 \mathrm{eV}$ corresponding to $\mathrm{Co}^{2+}$ state in $\mathrm{CoFe}_{2} \mathrm{O}_{4}$ state is also visible [50]. This peak increases with annealing temperature of $400{ }^{\circ} \mathrm{C}$ and $600{ }^{\circ} \mathrm{C}$ with relative decrease in peak at $782.0 \mathrm{eV}$. The core level of $\mathrm{B} 1 \mathrm{~s}$ in $\mathrm{AD}$ sample shows a single peak centered at $191.8 \mathrm{eV}$ corresponding to $\mathrm{B}-\mathrm{O}$ species in $\mathrm{B}_{2} \mathrm{O}_{3}$ and $\mathrm{FeBO}_{3}$. $\mathrm{B} 1 \mathrm{~s}$ spectra in AN200 and AN400 samples show the same peaks. For AN600, the spectra are deconvoluted in two peaks centered at $191.5 \mathrm{eV}$ and $192.5 \mathrm{eV}$ assigned to $\mathrm{B}-\mathrm{O}$ and $\mathrm{B}-\mathrm{Fe}$ species formed due to segregation of $\mathrm{B}_{2} \mathrm{O}_{3}$ and $\mathrm{FeBO}_{3}$ phases respectively [51, 52]. Single peak at $531.6 \mathrm{eV}$ corresponding to $\mathrm{Fe}^{3+} / \mathrm{Co}^{2+}$ and $\mathrm{FeBO}_{3}$ species is visible in spectra of $\mathrm{O} 1 \mathrm{~s}$ level for $\mathrm{AD}$ and $\mathrm{AN} 200$ coatings. In addition to this peak, two small peaks at $529.9 \mathrm{eV}$ and $532.4 \mathrm{eV}$ attributed to $\mathrm{O}$ in $\mathrm{CoFe}_{2} \mathrm{O}_{4}$ [50] and $\mathrm{B}_{2} \mathrm{O}_{3}$ [53] phases, respectively, are also observed for AN400 coating. At $600{ }^{\circ} \mathrm{C}$, the spectra is dominated by the peak at $529.9 \mathrm{eV}$ due to $\mathrm{O}$ in $\mathrm{CoFe}_{2} \mathrm{O}_{4}$ phase.

As XPS is a surface sensitive technique, the above results could only identify the surface species and thus no metallic peaks were detected, as seen from XRD data. The XPS results indicate that for $\mathrm{AD}$ coating, $\mathrm{Co}$ and $\mathrm{Fe}$ are mostly present in hydroxide state formed due to the ex-situ XPS measurement. Annealing at $200{ }^{\circ} \mathrm{C}$ slightly modifies the surface by initiating the formation of $\mathrm{CoFe}_{2} \mathrm{O}_{4}$ phase whose content increases at $400{ }^{\circ} \mathrm{C}$. However, complete crystallization of $\mathrm{CoFe}_{2} \mathrm{O}_{4}$ takes place at the highest temperature of $600{ }^{\circ} \mathrm{C}$ with separation of $\mathrm{FeBO}_{3}$ and $\mathrm{B}_{2} \mathrm{O}_{3}$ species on the surface. The XPS results are in good agreement with TEM and XRD results where partial crystallization of oxides takes place at $400{ }^{\circ} \mathrm{C}$ while complete crystallization occurs upon formation of urchin structures with NWs exhibiting $\mathrm{CoFe}_{2} \mathrm{O}_{4}$ structure at $600{ }^{\circ} \mathrm{C}$.

The electrochemical experiments for OER are done in two steps; firstly, the synthesized coating is evaluated for OER at different annealed temperatures (Fig. 3a) to probe the effect of morphology on the catalytic performance of the coatings. Secondly, the best performing catalyst is compared to single oxide coatings and without boron film (Fig. 5a) to understand the synergy of the phases and the role of individual elements for OER. To evaluate the electrochemical performance of all the synthesized samples, the films were deposited on FTO electrodes and tested for electrochemical water oxidation in a three-cell configuration. Before measurements, the electrodes were subjected to cyclic voltammetry cycles in the potential range of $-0.24 \mathrm{~V}$ to $1.76 \mathrm{~V}(\mathrm{~V}$ 

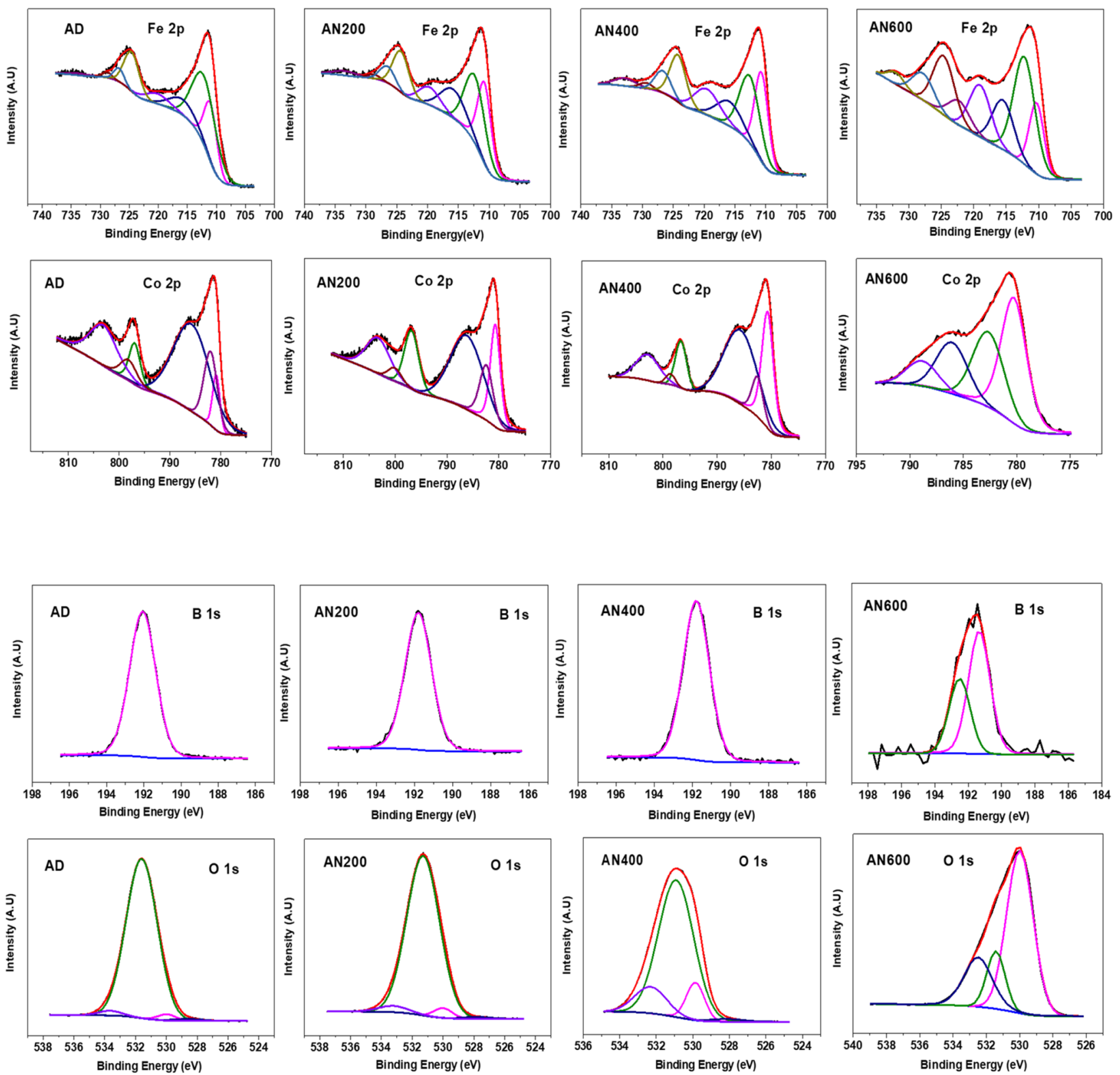

Fig. 2 XPS spectra of Fe 2p, Co 2p, B 1s and O 1s levels for as-deposited and annealed samples

vs. SCE) in order to obtain a stable response and to remove eventual surface impurities. iR-corrected linear polarization curves of all the coatings (as-deposited and annealed) and $\mathrm{RuO}_{2}$ nanoparticles are shown in Fig. $3 \mathrm{a}$ and the values obtained from these curves are summarized in Table S1. The best results are obtained for AN400 sample with an overpotential of $315 \mathrm{mV}$ at $10 \mathrm{~mA} / \mathrm{cm}^{2}$, which is much lower than other samples, including $\mathrm{RuO}_{2}(370 \mathrm{mV})$. AN400 also shows the lowest Tafel slope value of $31.5 \mathrm{mV} / \mathrm{dec}$, while AN600 and $\mathrm{RuO}_{2}$ exhibit higher Tafel slopes of 65.8 and $88.3 \mathrm{mV} /$ dec, respectively (Fig. 3b). This implies that the 3D urchin structure formed by completely crystallized NWs with high surface area are least active and the core-shell structure with partially crystallized shell are the most active for OER. This is consistent with the report by Jiang et al. [54] where partially crystalline Ni borate catalysts exhibited better OER activity than amorphous as well as completely crystalline catalysts. Thus, in the present case, owing to the partially crystalline nature of AN400, it exhibits better OER rates.

The graphs shown in Fig. 3 a do not represent the intrinsic activity of the films and are influenced by the contributions from surface area. Electrochemical surface area 

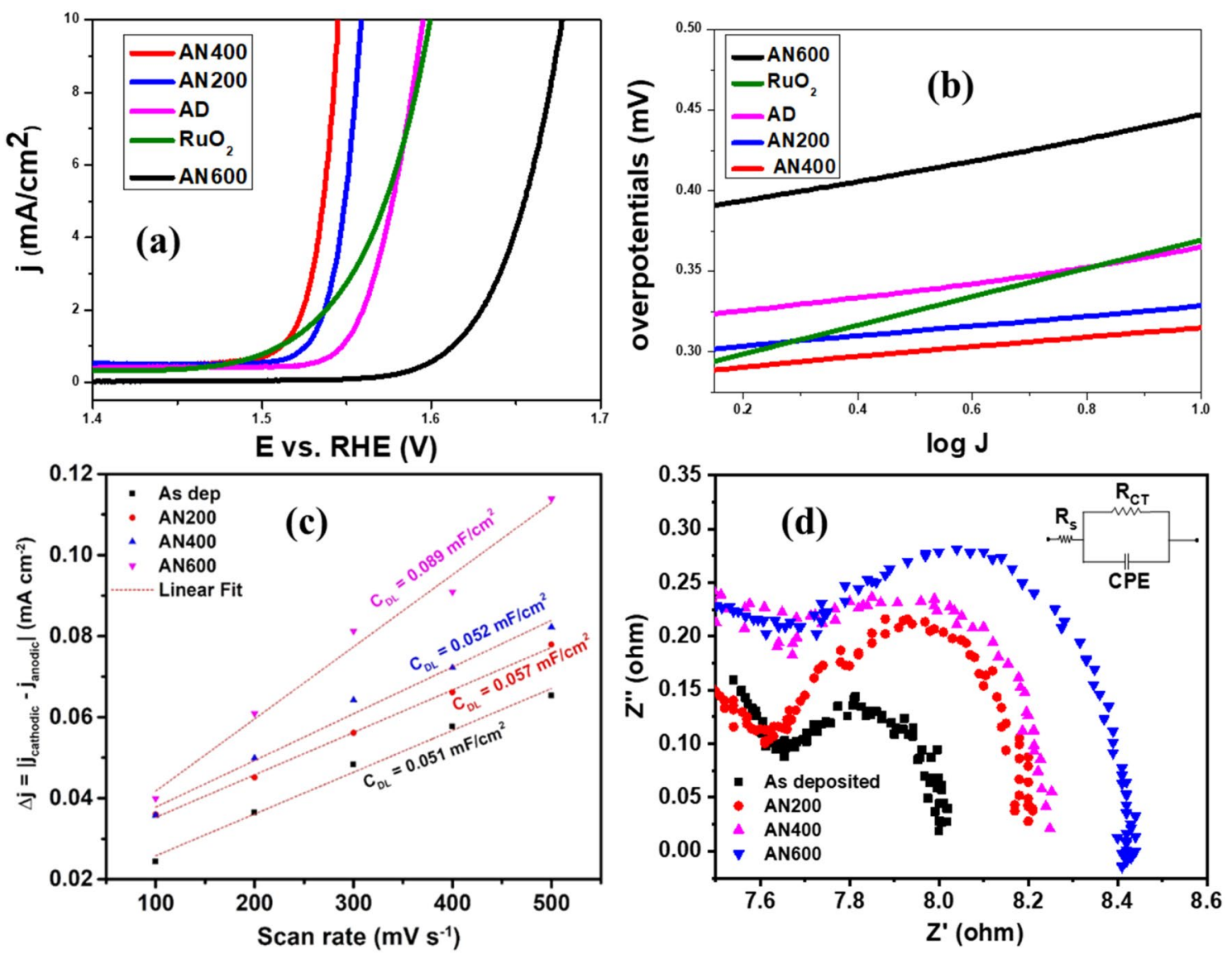

Fig. 3 a iR compensated LSV curves and $\mathbf{b}$ Tafel plots for as-deposited, annealed samples and $\mathrm{RuO}_{2}$, c plot representing the difference in cathodic and anodic current density against the scan rate to determine

$\mathrm{C}_{\mathrm{DL}}$ and $\mathbf{d}$ EIS graph at $0.5 \mathrm{~V}$ (vs OCP) for as-deposited and annealed samples respectively

Another factor that can affect the performance of a (ESA) of the films was estimated indirectly by determining the value of double layer capacitance $\left(\mathrm{C}_{\mathrm{DL}}\right)$ [26]. Figure $\mathrm{S} 1$ demonstrates the $\mathrm{CV}$ curves for all the films at increasing scan rates. From these graphs, the difference between the cathodic and anodic current densities was calculated and plotted against respective scan rates, to determine the value of $C_{D L}$. As seen in Fig. $3 c$, the value of $C_{D L}$ and hence the ESA is the highest for AN600 while that of other films are nearly the same. This result matches well with the SEM images where AD, AN200 and AN400 films show similar particulate morphology while AN600 showed formation of NWs on the surface. Owing to these NWs, AN600 presents more surface area for adsorption of reactant species from the electrolyte. Even with the maximum active surface area for OER, AN600 fails to exhibit the best electrochemical activity, showing that the number of active adsorption sites is not the rate determining step in electrochemistry. On the other hand, despite having similar ESA as AN200 and AD films, AN400 shows the highest OER rate, which must be credited to its partially crystalline phase [54]. catalyst is the charge transfer resistance (Rct) across the electrode/electrolyte interface. Rct was determined by electrochemical impedance spectroscopy (EIS) using an equivalent circuit model of two resistances and a constant phase element to fit the obtained Nyquist plots. Figure 3d shows the obtained Nyquist plots for all the samples at 0.5 $\mathrm{V}$ (vs OCP). AD coating establishes lowest resistance for charge transfer owing to the metallic nature of the coating. Approximately same $R_{C T}$ value is recorded for AN200 and AN400 due to similar core-shell structure with partially oxidized shell over metallic core. On the other hand, the AN600 establishes highest value of $\mathrm{R}_{\mathrm{CT}}$ thus suggesting that the crystallized NWs although acquiring high surface area offer higher resistance for the transfer of charges across the interface. Above results indicate that the morphology with high surface area is not relevant in the present case, possibly because of the crystalline nature of NWs. However, this aspect deserves further investigation.

In order to verify the role of crystalline oxide on the surface, it is imperative to identify the in-situ formed redox 
species by performing slow CV scans in the pre-OER potential region. As reported by Chen et al. [41] and Teng et al. [55], the position and intensity of pre-oxidation peak varies with Fe content and also defines the OER activity of $\mathrm{Co}-\mathrm{Fe}-\mathrm{B}-\mathrm{O}$ powder system. In the first cycle of anodic scan for AN400 (Fig. 4a), two oxidation peaks were observed, where the first peak is in the form of a shoulder at $1.21 \mathrm{~V}$ (vs RHE) while the second peak is at $1.31 \mathrm{~V}$ (vs RHE). The occurrence of first peak indicates formation of $\mathrm{Co}^{3+}$ species in the form of $\mathrm{CoOOH}$ on the surface of the coating which later gets converted to $\mathrm{Co}^{4+}\left(\mathrm{CoO}_{2}\right)$ at further oxidation potential [26]. In the reverse scan, a shoulder at 1.43 $\mathrm{V}$ and peak at $1.1 \mathrm{~V}$ is assigned to reduction of $\mathrm{CoO}_{2}$ and $\mathrm{CoOOH}$, respectively, to finally $\mathrm{Co}^{2+}$ species. In successive scan, only peak related to reversible transformation from $\mathrm{Co}^{2+}$ to $\mathrm{Co}^{3+}$ is observed in redox cycle, while the formation of $\mathrm{CoO}_{2}$ is expected to occur during anodic process. As per previous report, ${ }^{*} \mathrm{OOH}$ species are the most vital intermediate species in the OER process and can lead to enhancement in performance, even though the DFT calculations suggest that the formation of $* \mathrm{OOH}$ species is thermodynamically very difficult step. Similar phenomenon is also observed for AN200 film (Fig. 4b), but the area under the peak of oxidation and reduction are much lower, thus suggesting formation of less number of active Co oxides, leading to lower OER activity than AN400. On the other hand, this oxide formation is not observed for AD as well as AN600 films (Fig. 4b). This clearly shows that transformation of $\mathrm{Co}^{2+}$ to $\mathrm{CoOOH}$ species is responsible for facilitating OER and hence AN400 sample shows the best performance. On the contrary, the stable crystalline phase of $\mathrm{CoFe}_{2} \mathrm{O}_{4}$ formed in NWs of urchin structure at $600{ }^{\circ} \mathrm{C}$ does not form $\mathrm{CoOOH}$ species on the surface.

To obtain better understanding of the changes in chemical states of the mixed oxide film due to water oxidation reaction, XPS studies were performed on AN400 film after OER (Fig. 4c-f). Post OER, Co 2p state shows a prominent peak at $780.1 \mathrm{eV}$ attributed to the formation of $\mathrm{Co}^{3+}$ species in $\mathrm{CoOOH}$, which is consistent with the results obtained from CV measurements. The peaks at 786.1 and $796.4 \mathrm{eV}$ correspond to the satellite features of $\mathrm{Co}$ in $\mathrm{Co}^{3+}$ oxidation state. O 1s spectra for post-OER AN400 film also shows an increase in the peak intensity associated with $* \mathrm{OOH}$ group $(529.5 \mathrm{eV})$ while maintaining the intense peak at $531.6 \mathrm{eV}$ due to $\mathrm{Fe}^{3+/} \mathrm{Co}^{2+}$ and $\mathrm{FeBO}_{3}$ species and minor peak at 532.4 $\mathrm{eV}$ of $\mathrm{O}$ in $\mathrm{B}_{2} \mathrm{O}_{3}$. As per previous reports, $\mathrm{Fe}$ compounds can easily form ${ }^{*} \mathrm{OOH}-$ like species and the $\mathrm{Fe}$ in $\mathrm{CoFeOx}$ catalyst plays a significant role in promoting the formation and stabilizing the $* \mathrm{OOH}-$ like species [41]. A higher concentration of $* \mathrm{OOH}$-like species leads to superior OER performance. For Fe $2 p$ state, the peak at $711.0 \mathrm{eV}$ corresponding to $\mathrm{Fe}^{3+}$ species shows an increase in intensity for post-OER sample. This peak was also observed in as prepared sample, as indicated by before-OER XPS, due to Fe being present in high oxidation state $\left(\mathrm{Fe}^{3+}\right)$. The higher BE peak at $718 \mathrm{eV}$ is also preserved. In case of B 1s state, post-OER film shows
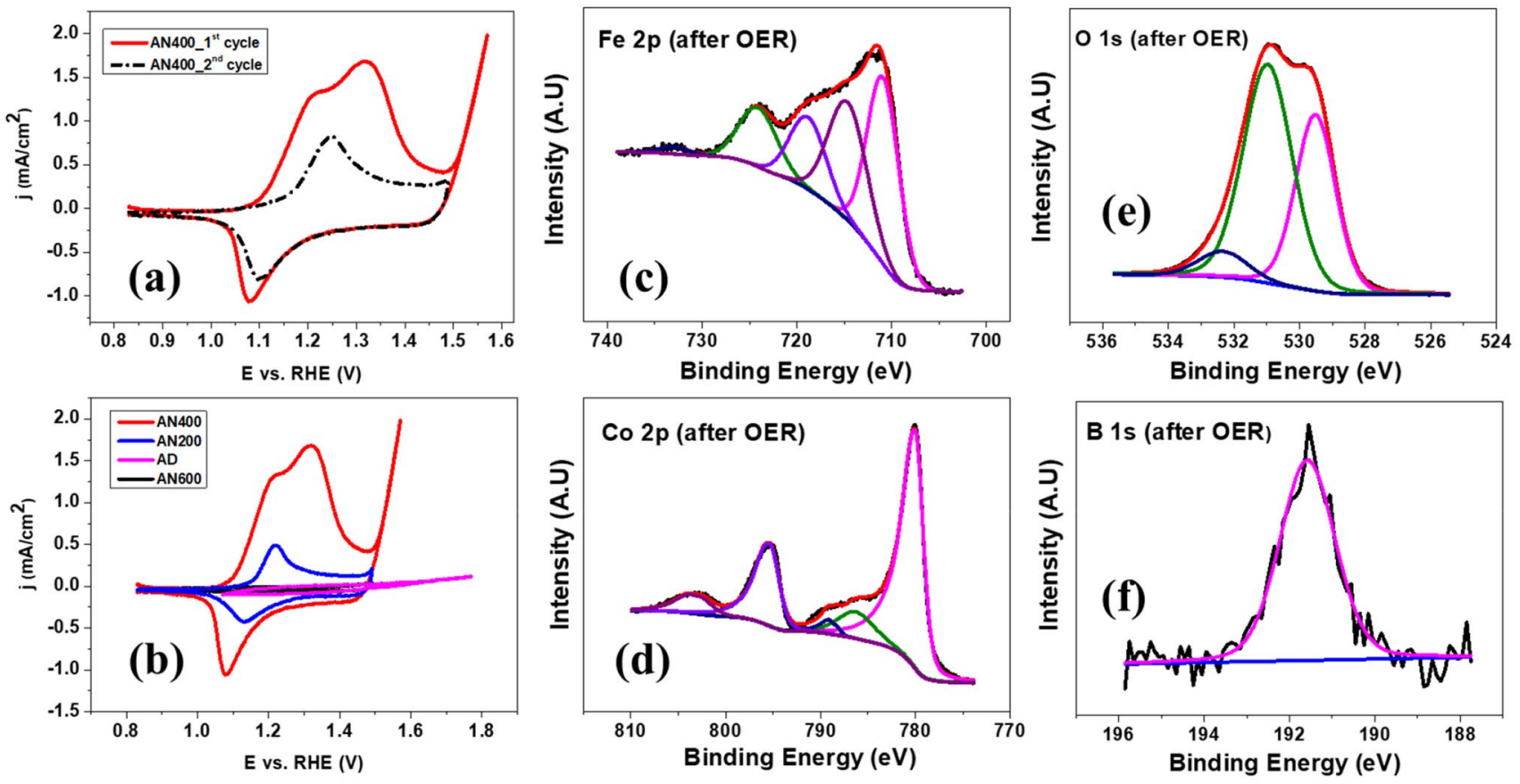

Fig. 4 a First two cycles of slow scan CV curves for AN400 sample and b slow scan CV curves for as-deposited and annealed samples, XPS spectra of $\mathbf{c}$ Fe 2p, d Co 2p, e O 1s and $\mathbf{f}$ B 1s levels for AN400 sample after OER 
a single peak at $191.6 \mathrm{eV}$, ascribed to $\mathrm{B}_{2} \mathrm{O}_{3}$, as also observed in pristine films before OER.

So far, it is well-established that AN400 film shows the best performance, owing to in-situ transformation of $\mathrm{Co}^{2+}$ species to large number of $\mathrm{CoOOH}$ active sites. Though $\mathrm{CoOOH}$ appears to be the active centre for OER, the role of Fe and B in the coating is still not clear. To illustrate the roles of $\mathrm{Co}, \mathrm{Fe}$ and $\mathrm{B}$ in the film, the performance of AN400 was compared with that of single oxide films of $\mathrm{CoOx}$ and $\mathrm{FeOx}$ (containing boron) and mixed oxide film deposited without boron (termed as AN400_2). It must be noted that these single oxide films were also deposited with exactly the same experimental conditions as that of AN400 coating. AN400 coating shows much superior electrochemical activity (Fig. 5a) and lower Tafel slope (Fig. S2) compared to the single oxides and AN400_2 films. To achieve the current density of $10 \mathrm{~mA} / \mathrm{cm}^{2}$, overpotentials of $315 \mathrm{mV}, 406 \mathrm{mV}, 421 \mathrm{mV}$ and $492 \mathrm{mV}$ were required for AN400, CoOx, AN400_2 and FeOx coatings, respectively (Table S2), indicating that the combination of $\mathrm{Co}, \mathrm{Fe}$ and $\mathrm{B}$ together yields the best performance. To isolate the roles of $\mathrm{Co}, \mathrm{Fe}$ and B, CV scans were recorded for AN400, CoOx, FeOx and AN400_2 films at a scan rate of $2 \mathrm{mV} / \mathrm{s}$ (Fig. 5b and c). On comparing the two mixed oxide films (Fig. 5b), AN400 and AN400_2, one can see that boron free sample (AN400_2) shows no redox peaks, while the sample with boron (AN400) shows prominent reversible redox peaks, corresponding to transformation of $\mathrm{Co}$ from $\mathrm{Co}^{2+}$ to higher oxidation states. This implies that the role of boron is to assist in formation of $\mathrm{Co}^{3+}$ states on the surface of the film. It has been reported that in case of Co-B films, B acts as the sacrificial element by donating electrons to $\mathrm{Co}$, thereby protecting it from forming stable oxides [56]. In the present case, boron plays a similar role of preventing complete oxidation of Co thus permitting it in forming $\mathrm{Co}^{3+}$ species on the surface. To illustrate the role of $\mathrm{Fe}, \mathrm{CV}$ scans of $\mathrm{CoOx}$ and $\mathrm{FeOx}$ films were analysed (Fig. 5c). The first anodic cycle for $\mathrm{CoOx}$ shows a main oxidation peak at $1.15 \mathrm{~V}$ (vs. RHE) along with two secondary shoulders at $1.07 \mathrm{~V}$ (vs. RHE) and $1.25 \mathrm{~V}$ (vs. RHE). During the reverse scan, a very small reduction peak is observed at $1.05 \mathrm{~V}$ (vs. RHE), indicating a quasi-reversible reaction. The successive scan displays no oxidation and reduction peaks, indicating that the oxidised species are not regenerated again. Thus, $\mathrm{CoOx}$ coatings show no stable active species and hence exhibit inferior electrochemical activity for OER. FeOx, on the other hand,
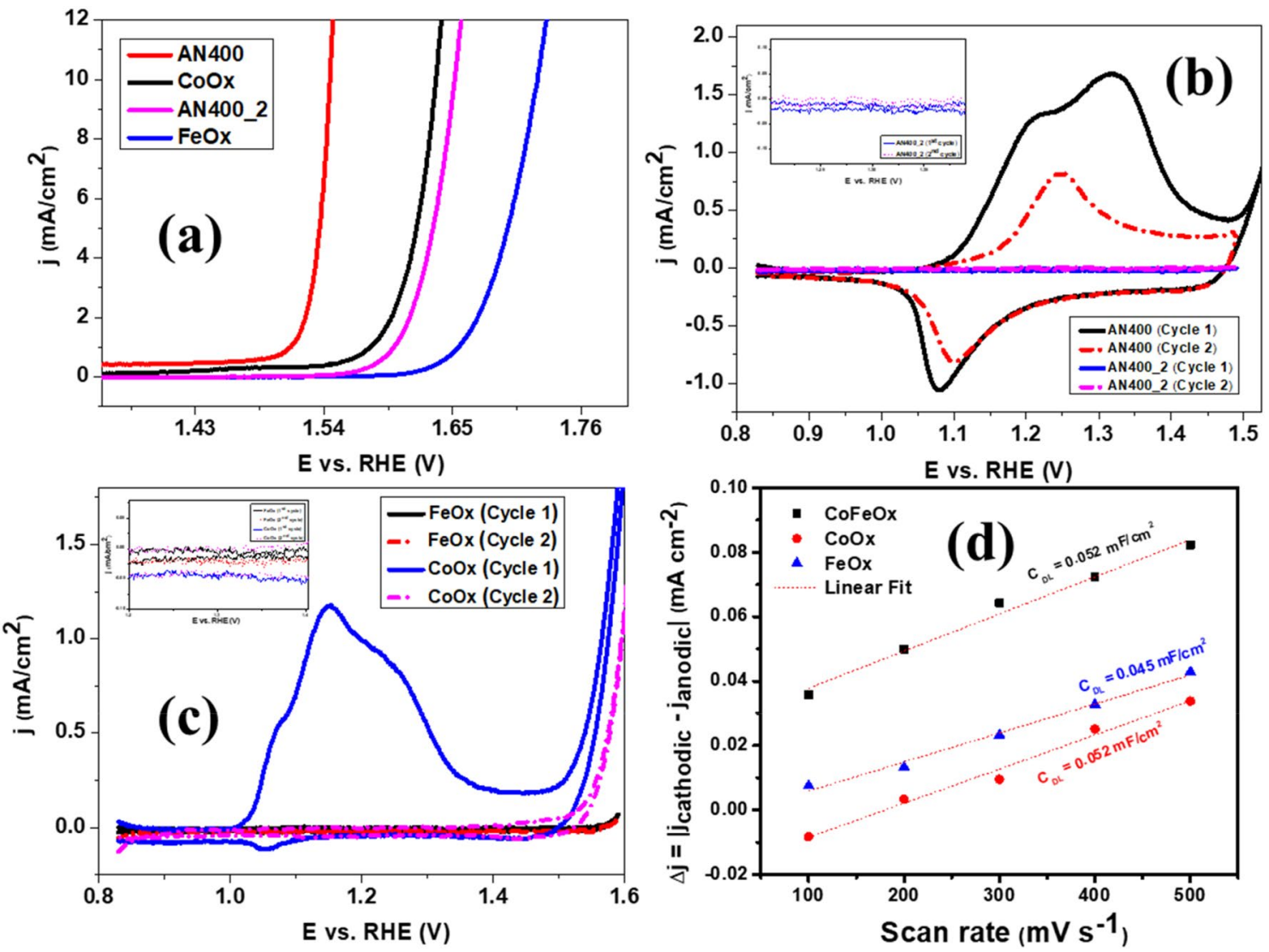

Fig. 5 a iR compensated LSV curves, slow scan CV curves for b AN400 and AN400_2 samples and $\mathbf{c}$ FeOx and CoOx samples and d plot representing the difference in cathodic and anodic current density against the scan rate to determine $\mathrm{C}_{\mathrm{DL}}$ 

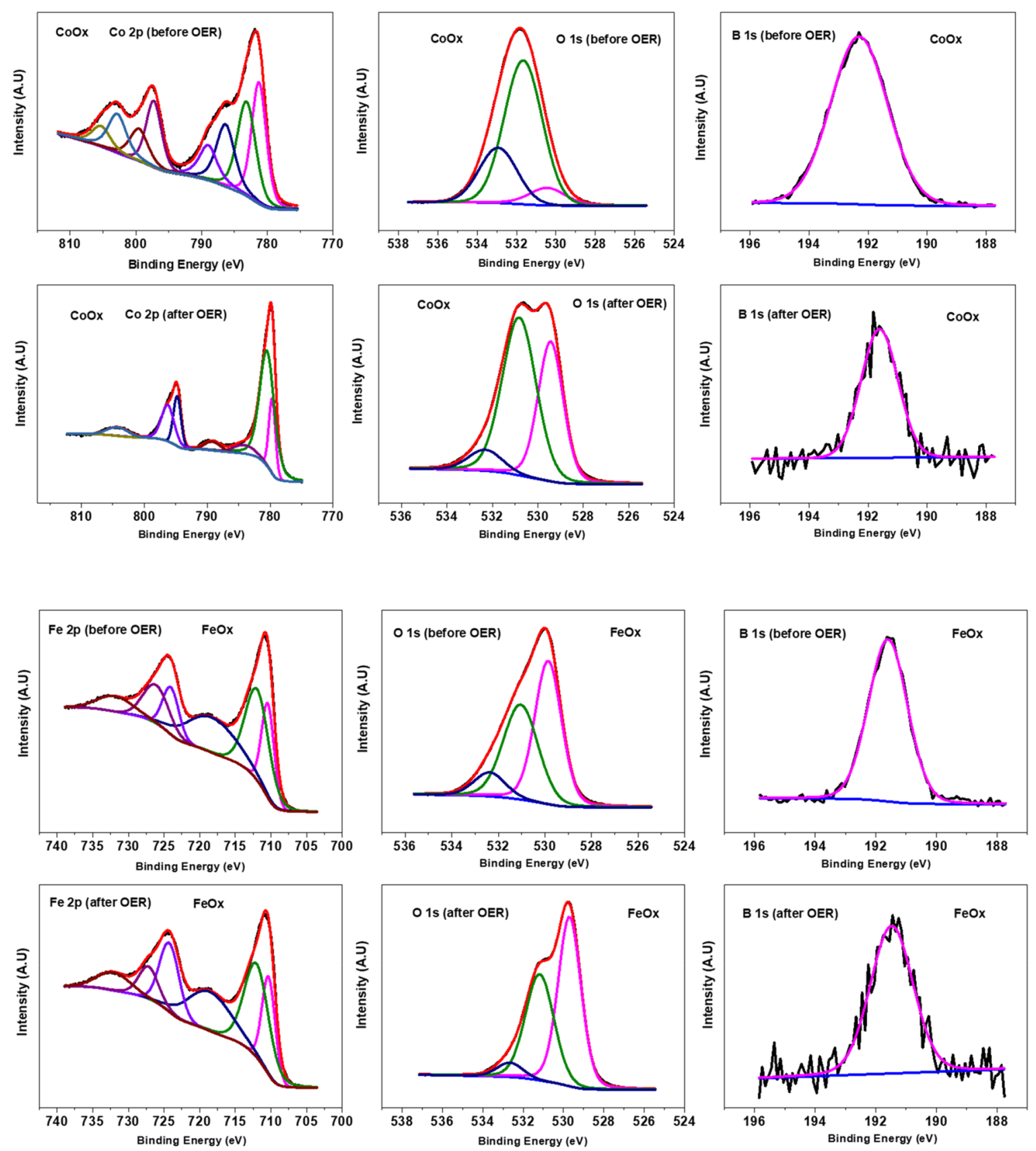

Fig. 6 XPS spectra of Co 2p, Fe 2p, B 1s and O 1s levels for CoOx and FeOx samples before and after OER

shows no redox peaks in both the cycles, suggesting that Fe doesn't undergo any oxidation in this potential regime. Thus FeOx lacks active sites for catalysing water oxidation, thereby displaying the worst OER performance. Only in the case of AN400 film, the redox peaks corresponding to the active $\mathrm{Co}^{3+}$ species are present consistently in all CV scans. This indicates that the oxidation chemistry of mixed oxide catalyst (AN400) containing $\mathrm{Co}$ and $\mathrm{Fe}$ is completely different than that of single oxides of $\mathrm{Co}$ and $\mathrm{Fe}$, under applied anodic potentials. Co oxide alone fails to regenerate oxide species on its surface, but the presence of Fe helps it in forming reversible species of Co in higher oxidation state, which in turn facilitates water oxidation reaction. Thus, in case of mixed oxide film (AN400), the role of B is to prevent complete oxidation of Co thus permitting it in forming $\mathrm{Co}^{3+}$ species which further transform to higher oxidation states, while Fe helps in reducing $\mathrm{Co}^{3+}$ to $\mathrm{Co}^{2+}$ so that it can be regenerated to active $\mathrm{Co}^{3+}$ species in successive cycles. To summarise, the primary catalytic sites for the $\mathrm{Co}-\mathrm{Fe}-\mathrm{B}-\mathrm{O}$ coatings for OER are Co sites which determine the electrocatalytic 

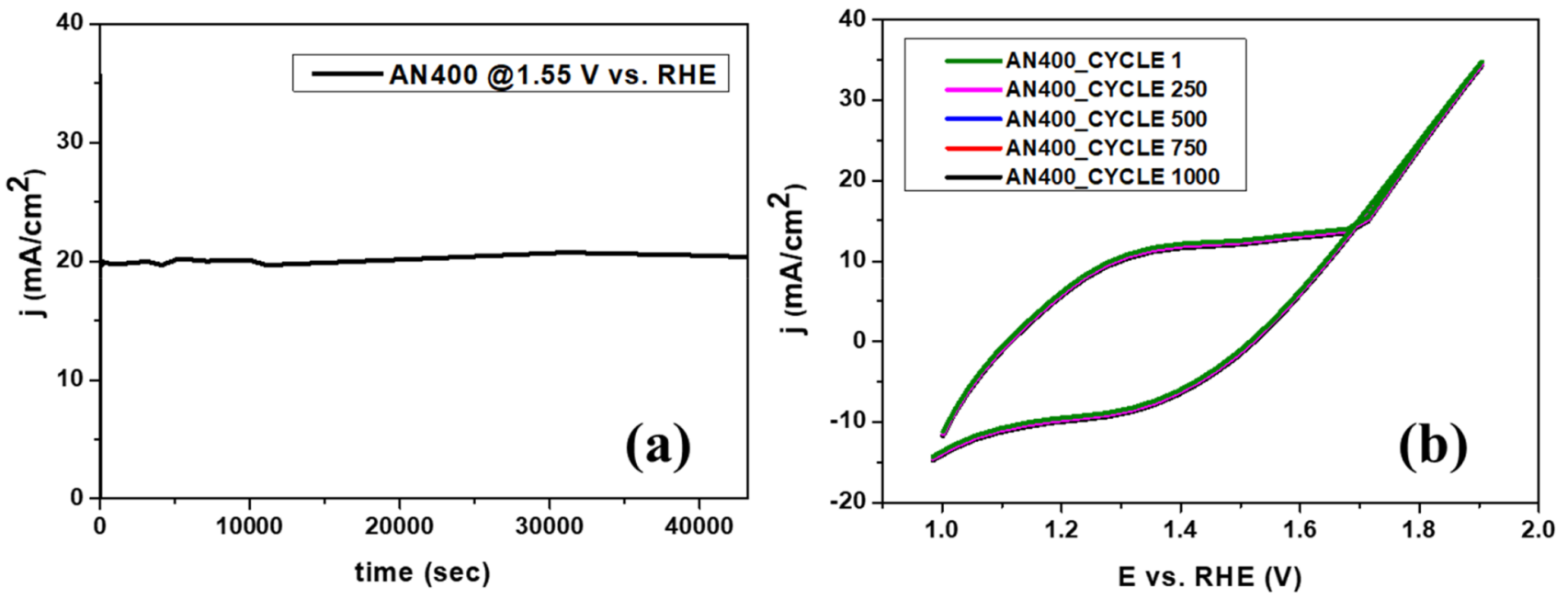

Fig. 7 a Chronoamperometric measurement demonstrating the stability of AN400 coatings during $12 \mathrm{~h}$, and b recyclability test by performing cyclic voltammetries on AN400 coating for 1000 cycles

performance of the coatings, whereas Fe and B play subsidiary roles in improving the activity of Co sites.

To further elucidate the difference between mixed oxide and single oxide films, $\mathrm{C}_{\mathrm{DL}}$ values were determined for $\mathrm{CoOx}$ and FeOx films (Fig. 5d). Figure S3 demonstrates the $\mathrm{CV}$ curves at increasing scan rates. The value of $\mathrm{C}_{\mathrm{DL}}$ and hence the ESA for CoOx film is the same as that obtained for AN400 film $\left(0.052 \mathrm{mF} / \mathrm{cm}^{2}\right)$, while FeOx exhibits a lower $\mathrm{C}_{\mathrm{DL}}$ value of $0.045 \mathrm{mF} / \mathrm{cm}^{2}$. This implies that the number of active adsorption sites in $\mathrm{CoOx}$ is the same as in AN400 film, which is understood as Co is the active site in both samples. However, despite having similar ESA, CoOx does not show the same performance as AN400 film due to the inability to regenerate after undergoing oxidation. Thus, the charge exchange effectiveness of the active sites/species is the dominating factor in determining the performance of the electrocatalyst as compared to the number of adsorption active sites.

XPS analysis were performed on single oxide films, $\mathrm{CoOx}$ and $\mathrm{FeOx}$, before and after OER to gain insights on the changes that occur and the phases that are formed upon OER (Fig. 6). In case of CoOx films before OER, Co $2 p_{3 / 2}$ XPS spectra display two peaks centered at 781.3 $\mathrm{eV}$ and $782.5 \mathrm{eV}$ corresponding to $\mathrm{Co}^{2+}$ in $\mathrm{Co}(\mathrm{OH})_{2}$ and $\mathrm{CoO}$ phases, respectively, along with the matching satellite peaks at $\mathrm{BE}$ of $\sim 786.0 \mathrm{eV}$ and $789.0 \mathrm{eV}$. On comparing these peaks of $\mathrm{Co} 2+$ in $\mathrm{Co} 2 \mathrm{p}$ level with that of mixed metal oxide (AN400) (780.8 and $782.0 \mathrm{eV}$ ) there is a shift of $0.5 \mathrm{eV}$ towards higher BE of single metal oxide. This indicates that cobalt is accepting electrons and is in a reduced form in mixed metal oxide film as compared to single oxide CoOx film. Post OER Co 2p spectra shows a dominant peak at $780.3 \mathrm{eV}$ corresponding to $\mathrm{CoOOH}$ phase similar as in mixed metal oxide film. In case of $\mathrm{O} 1 \mathrm{~s}$ XPS level, the peaks at $530.4 \mathrm{eV}, 531.9 \mathrm{eV}$ and $533.0 \mathrm{eV}$ assigned to $\mathrm{O}$ in $\mathrm{CoO}$, $\mathrm{Co}(\mathrm{OH})_{2}$ and $\mathrm{B}_{2} \mathrm{O}_{3}$ in single metal oxide ( $\mathrm{AN} 400$ ) indicates that oxygen is also in a reduced state in the case of mixed metal oxide films. XPS spectra for Fe 2p level in FeOx film before OER displays two peaks at $710.4 \mathrm{eV}$ and at 712.0 $\mathrm{eV}$ corresponding to $\mathrm{Fe}^{3+}$ in $\alpha-\mathrm{Fe}_{2} \mathrm{O}_{3}$ and $\mathrm{FeBO}_{3}$ phases. These peak positions are shifted tolower BE by $0.4-0.8 \mathrm{eV}$ than that observed for $\mathrm{Fe} 2 \mathrm{p}$ level in mixed metla oxide film (710.6 eV and 712.8 eV), thus suggesting that the Fe in the mixed metal oxide film plays the role of donating electrons and reducing cobalt. Post OER Fe 2p level for FeOx film shows almost similar peaks and intensities as that of before OER. Thus, the XPS confirms the role of all the elements in the mixed metal oxide films with Fe donating electrons to Co and helping the reduction of Co oxide species which helps in regenerating active species for OER in each cycle.

It is of paramount importance to study the stability and recyclability of these coatings for practical applications. For stability tests, chronoamperometric measurements were done on AN400 film for 12 h (Fig. 7a). The film displays good stability and produces an almost constant current density at $1.55 \mathrm{~V}$ vs. RHE. AN400 coatings were also tested for their recyclability by performing cyclic voltammetry scans for 1000 cycles in $1 \mathrm{M} \mathrm{KOH}$ solution. The films show favourable results with no signs of deterioration even after 
the 1000th cycle (Fig. 7b), thereby making the coatings suitable for applications.

\section{Conclusions}

$\mathrm{Co}-\mathrm{Fe}-\mathrm{B}-\mathrm{O}$ coatings were successfully synthesized by PLD for electrochemical water oxidation. Investigating on morphological and structural transformation, upon annealing at different temperatures, reveals that OER performance is inferior for high surface area urchin-like morphology with well crystallized nanowires in $\mathrm{CoFe}_{2} \mathrm{O}_{4}$ phase. The synthesized coatings annealed at $400{ }^{\circ} \mathrm{C}$ showed core-shell like structure with partially cystallized shell to produce excellent electrochemical performance towards water oxidation reactions with an overpotential of $315 \mathrm{mV}$ at $10 \mathrm{~mA} / \mathrm{cm}^{2}$ and Tafel slope of $31.5 \mathrm{mV} / \mathrm{dec}$. The role of $\mathrm{Fe}$ and $\mathrm{B}$ in influencing the activity of Co sites was investigated by testing control samples. The mixed metal oxide coating exhibits superior electrochemical activity compared to control samples of $\mathrm{CoOx}, \mathrm{FeOx}$ and AN400_2 (without boron). It was found that B prevents complete oxidation of Co thus permitting it in forming $\mathrm{Co}^{3+}$ species $(\mathrm{CoOOH})$, while $\mathrm{Fe}$ assists in reducing $\mathrm{Co}^{3+}$ to $\mathrm{Co}^{2+}$ so that these species are regenerated in the successive cycles. Moreover, it was also established that the performance of an electrocatalyst is mainly driven by the charge exchange effectiveness of each site as compared to the number of surface active sites. Stability and recyclability tests done on mixed metal oxide coatings showed their robustness thus indicating their possible industrial applications.

Supplementary Information The online version contains supplementary material available at https://doi.org/10.1007/s10562-021-03642-4.

Funding Open access funding provided by Universita degli Studi di Trento within the CRUI-CARE Agreement.

Open Access This article is licensed under a Creative Commons Attribution 4.0 International License, which permits use, sharing, adaptation, distribution and reproduction in any medium or format, as long as you give appropriate credit to the original author(s) and the source, provide a link to the Creative Commons licence, and indicate if changes were made. The images or other third party material in this article are included in the article's Creative Commons licence, unless indicated otherwise in a credit line to the material. If material is not included in the article's Creative Commons licence and your intended use is not permitted by statutory regulation or exceeds the permitted use, you will need to obtain permission directly from the copyright holder. To view a copy of this licence, visit http://creativecommons.org/licenses/by/4.0/.

\section{References}

1. Ju H, Giddey S, Badwal SPS (2017) The role of nanosized SnO2 in Pt-based electrocatalysts for hydrogen production in methanol assisted water electrolysis. Electrochim Acta 229:39-47. https:// doi.org/10.1016/j.electacta.2017.01.106

2. Shi Y, Zhang B (2016) Recent advances in transition metal phosphide nanomaterials: synthesis and applications in hydrogen evolution reaction. Chem Soc Rev 45:1529-1541. https://doi.org/10. 1039/C5CS00434A

3. Anantharaj S, Ede SR, Karthick K et al (2018) Precision and correctness in the evaluation of electrocatalytic water splitting: revisiting activity parameters with a critical assessment. Energy Environ Sci 11:744-771. https://doi.org/10.1039/C7EE03457A

4. Zeng M, Li Y (2015) Recent advances in heterogeneous electrocatalysts for the hydrogen evolution reaction. J Mater Chem A 3:14942-14962. https://doi.org/10.1039/C5TA02974K

5. Xiao C, Zhang B, Li D (2017) Partial-sacrificial-template synthesis of $\mathrm{Fe} / \mathrm{Ni}$ phosphides on Ni foam: a strongly stabilized and efficient catalyst for electrochemical water splitting. Electrochim Acta 242:260-267. https://doi.org/10.1016/j.electacta.2017.05. 015

6. Khalate SA, Kadam SA, Ma Y-R et al (2019) Hydrothermally synthesized Iron Phosphate Hydroxide thin film electrocatalyst for electrochemical water splitting. Electrochim Acta 319:118-128. https://doi.org/10.1016/j.electacta.2019.06.162

7. Godwin I, Rovetta A, Lyons M, Coleman J (2018) Electrochemical water oxidation: the next five years. Curr Opin Electrochem 7:31-35. https://doi.org/10.1016/j.coelec.2017.09.025

8. Matsumoto Y, Sato E (1986) Electrocatalytic properties of transition metal oxides for oxygen evolution reaction. Mater Chem Phys 14:397-426. https://doi.org/10.1016/0254-0584(86)90045-3

9. Trasatti S (1980) Electrocatalysis by oxides-attempt at a unifying approach. J Electroanal Chem Interfacial Electrochem 111:125131. https://doi.org/10.1016/S0022-0728(80)80084-2

10. Jiao F, Frei H (2009) Nanostructured cobalt oxide clusters in mesoporous silica as efficient oxygen-evolving catalysts. Angew Chem Int Ed 48:1841-1844. https://doi.org/10.1002/anie.20080 5534

11. Chen S, Thind SS, Chen A (2016) Nanostructured materials for water splitting - state of the art and future needs: A mini-review. Electrochem commun 63:10-17. https://doi.org/10.1016/j.elecom. 2015.12.003

12. Ma Q, Li B, Huang F et al (2019) Incorporating iron in nickel cobalt layered double hydroxide nanosheet arrays as efficient oxygen evolution electrocatalyst. Electrochim Acta 317:684-693. https://doi.org/10.1016/j.electacta.2019.06.019

13. Yu C, Xu F, Luo L et al (2019) Bimetallic Ni-Co phosphide nanosheets self-supported on nickel foam as high-performance electrocatalyst for hydrogen evolution reaction. Electrochim Acta 317:191-198. https://doi.org/10.1016/j.electacta.2019. 05.150

14. Qi Y, Zhang Q, Meng S et al (2020) Iron-doped nickle cobalt ternary phosphide hyperbranched hierarchical arrays for efficient overall water splitting. Electrochim Acta 334:135633. https://doi. org/10.1016/j.electacta.2020.135633

15. Berardi S, La Ganga G, Natali M et al (2012) Photocatalytic water oxidation: tuning light-induced electron transfer by molecular Co4O4 cores. J Am Chem Soc 134:11104-11107. https://doi.org/ 10.1021/ja303951z

16. Zhu J, Yin Z, Yang D et al (2013) Hierarchical hollow spheres composed of ultrathin $\mathrm{Fe} 2 \mathrm{O} 3$ nanosheets for lithium storage and photocatalytic water oxidation. Energy Environ Sci 6:987-993. https://doi.org/10.1039/C2EE24148J 
17. Wang J, Cui W, Liu Q et al (2016) Recent progress in cobalt-based heterogeneous catalysts for electrochemical water splitting. Adv Mater 28:215-230. https://doi.org/10.1002/adma.201502696

18. Han L, Dong S, Wang E (2016) Transition-metal (Co, Ni, and $\mathrm{Fe}$ )-based electrocatalysts for the water oxidation reaction. Adv Mater 28:9266-9291. https://doi.org/10.1002/adma.201602270

19. Rahman G, Joo O-S (2013) Electrodeposited nanostructured $\alpha-\mathrm{Fe} 2 \mathrm{O} 3$ thin films for solar water splitting: Influence of Pt doping on photoelectrochemical performance. Mater Chem Phys 140:316-322. https://doi.org/10.1016/j.matchemphys.2013.03.042

20. Zhang Z, Gao C, Li Y et al (2016) Enhanced charge separation and transfer through $\mathrm{Fe} 2 \mathrm{O} 3 / \mathrm{ITO}$ nanowire arrays wrapped with reduced graphene oxide for water-splitting. Nano Energy 30:892899. https://doi.org/10.1016/j.nanoen.2016.08.059

21. Orlandi M, Caramori S, Ronconi F et al (2014) Pulsed-laser deposition of nanostructured iron oxide catalysts for efficient water oxidation. ACS Appl Mater Interfaces 6:6186-6190. https://doi. org/10.1021/am501021e

22. Orlandi M, Dalle Carbonare N, Caramori S et al (2016) Porous versus compact nanosized $\mathrm{Fe}$ (III)-based water oxidation catalyst for photoanodes functionalization. ACS Appl Mater Interfaces 8:20003-20011. https://doi.org/10.1021/acsami.6b05135

23. Trotochaud L, Ranney JK, Williams KN, Boettcher SW (2012) Solution-cast metal oxide thin film electrocatalysts for oxygen evolution. J Am Chem Soc 134:17253-17261. https://doi.org/10. 1021/ja307507a

24. Sivula K, Zboril R, Le Formal F et al (2010) Photoelectrochemical water splitting with mesoporous hematite prepared by a solution-based colloidal approach. J Am Chem Soc 132:7436-7444. https://doi.org/10.1021/ja101564f

25. Tüysüz H, Hwang YJ, Khan SB et al (2013) Mesoporous Co3O4 as an electrocatalyst for water oxidation. Nano Res 6:47-54. https://doi.org/10.1007/s12274-012-0280-8

26. Gupta S, Yadav A, Bhartiya S et al (2018) Co oxide nanostructures for electrocatalytic water-oxidation: effects of dimensionality and related properties. Nanoscale 10:8806-8819. https://doi.org/10. 1039/C8NR00348C

27. Jiao F, Frei H (2010) Nanostructured cobalt and manganese oxide clusters as efficient water oxidation catalysts. Energy Environ Sci 3:1018-1027. https://doi.org/10.1039/C002074E

28. Sen SH, Agiral A, Bachmeier A, Frei H (2012) Visible lightinduced hole injection into rectifying molecular wires anchored on $\mathrm{Co} 3 \mathrm{O} 4$ and $\mathrm{SiO} 2$ nanoparticles. J Am Chem Soc 134:1710417116. https://doi.org/10.1021/ja306162g

29. Zhang M, de Respinis M, Frei H (2014) Time-resolved observations of water oxidation intermediates on a cobalt oxide nanoparticle catalyst. Nat Chem 6:362

30. Kargar A, Yavuz S, Kim TK et al (2015) Solution-processed $\mathrm{CoFe} 2 \mathrm{O} 4$ nanoparticles on 3D carbon fiber papers for durable oxygen evolution reaction. ACS Appl Mater Interfaces 7:1785117856. https://doi.org/10.1021/acsami.5b04270

31. Lu X-F, Gu L-F, Wang J-W et al (2017) Bimetal-organic framework derived $\mathrm{CoFe} 2 \mathrm{O} 4 / \mathrm{C}$ porous hybrid nanorod arrays as highperformance electrocatalysts for oxygen evolution reaction. Adv Mater 29:1604437. https://doi.org/10.1002/adma.201604437

32. Yan W, Cao X, Tian J et al (2016) Nitrogen/sulfur dual-doped $3 \mathrm{D}$ reduced graphene oxide networks-supported $\mathrm{CoFe} 2 \mathrm{O} 4$ with enhanced electrocatalytic activities for oxygen reduction and evolution reactions. Carbon N Y 99:195-202. https://doi.org/10. 1016/j.carbon.2015.12.011

33. Warang T, Patel N, Santini A et al (2012) Pulsed laser deposition of $\mathrm{Co} 3 \mathrm{O} 4$ nanoparticles assembled coating: role of substrate temperature to tailor disordered to crystalline phase and related photocatalytic activity in degradation of methylene blue. Appl
Catal A Gen 423-424:21-27. https://doi.org/10.1016/j.apcata. 2012.02.037

34. Guo Q, Shi W, Liu F et al (2013) Effects of oxygen gas pressure on properties of iron oxide films grown by pulsed laser deposition. J Alloys Compd 552:1-5. https://doi.org/10.1016/j.jallcom.2012. 10.088

35. Miotello A, Patel N (2013) Pulsed laser deposition of clusterassembled films for catalysis and the photocatalysis relevant to energy and the environment. Appl Surf Sci 278:19-25. https:// doi.org/10.1016/j.apsusc.2012.11.073

36. Fàbrega C, Murcia-López S, Monllor-Satoca D et al (2016) Efficient WO3 photoanodes fabricated by pulsed laser deposition for photoelectrochemical water splitting with high faradaic efficiency. Appl Catal B Environ 189:133-140. https://doi.org/10.1016/j. apcatb.2016.02.047

37. Blakemore JD, Gray HB, Winkler JR, Müller AM (2013) Co3O4 nanoparticle water-oxidation catalysts made by pulsed-laser ablation in liquids. ACS Catal 3:2497-2500. https://doi.org/10.1021/ cs400639b

38. Edla R, Tonezzer A, Orlandi M et al (2017) 3D hierarchical nanostructures of iron oxides coatings prepared by pulsed laser deposition for photocatalytic water purification. Appl Catal B Environ 219:401-411. https://doi.org/10.1016/j.apcatb.2017.07.063

39. Edla R, Patel N, Orlandi M et al (2015) Highly photo-catalytically active hierarchical 3D porous/urchin nanostructured $\mathrm{Co} 3 \mathrm{O} 4$ coating synthesized by pulsed laser deposition. Appl Catal B Environ 166-167:475-484. https://doi.org/10.1016/j.apcatb.2014.11.060

40. Popat Y, Orlandi M, Patel N et al (2019) Pulsed laser deposition of $\mathrm{CoFe} 2 \mathrm{O} 4 / \mathrm{CoO}$ hierarchical-type nanostructured heterojuction forming a Z-scheme for efficient spatial separation of photoinduced electron-hole pairs and highly active surface area. Appl Surf Sci 489:584-594. https://doi.org/10.1016/j.apsusc.2019.05.314

41. Chen H, Ouyang S, Zhao M et al (2017) Synergistic activity of $\mathrm{Co}$ and $\mathrm{Fe}$ in amorphous $\mathrm{Cox}-\mathrm{Fe}-\mathrm{B}$ catalyst for efficient oxygen evolution reaction. ACS Appl Mater Interfaces 9:40333-40343. https://doi.org/10.1021/acsami.7b13939

42. Liu G, He D, Yao R et al (2018) Amorphous CoFeBO nanoparticles as highly active electrocatalysts for efficient water oxidation reaction. Int J Hydrog Energy 43:6138-6149. https://doi.org/10. 1016/j.ijhydene.2018.01.191

43. Bonelli M, Cestari C, Miotello A (1999) Pulsed laser deposition apparatus for applied research. Meas Sci Technol 10:27-30. https://doi.org/10.1088/0957-0233/10/3/024

44. Mazzi A, Orlandi M, Patel N, Miotello A (2018) Laser-inducing extreme thermodynamic conditions in condensed matter to produce nanomaterials for catalysis and the photocatalysis BT. In: Ossi PM (ed) Advances in the application of lasers in materials science. Springer International Publishing, Cham, pp 89-106

45. Zamkovskaya A, Maksimova E, Nauhatsky I, Shapoval M (2017) $\mathrm{X}$-ray diffraction investigations of the thermal expansion of iron borate FeBO3 crystals. J Phys Conf Ser 929:12030. https://doi. org/10.1088/1742-6596/929/1/012030

46. Grosvenor AP, Kobe BA, Biesinger MC, McIntyre NS (2004) Investigation of multiplet splitting of Fe 2p XPS spectra and bonding in iron compounds. Surf Interface Anal 36:1564-1574. https:// doi.org/10.1002/sia.1984

47. Konno H, Nagayama M (1980) X-ray photoelectron spectra of hexavalent iron. J Electron Spectrosc Relat Phenom 18:341-343. https://doi.org/10.1016/0368-2048(80)80021-1

48. McIntyre NS, Zetaruk DG (1977) X-ray photoelectron spectroscopic studies of iron oxides. Anal Chem 49:1521-1529. https:// doi.org/10.1021/ac50019a016

49. Mattogno G, Ferragina C, Massucci MA et al (1988) X-ray photoelectron spectroscopic evidence of interlayer complex formation between $\mathrm{Co}(\mathrm{II})$ and $\mathrm{N}$-heterocycles in $\alpha-\mathrm{Zr}(\mathrm{hpo} 4) 2 \cdot \mathrm{H} 2 \mathrm{O}$. J 
Electron Spectrosc Relat Phenom 46:285-295. https://doi.org/10. 1016/0368-2048(88)85026-6

50. McIntyre NS, Cook MG (1975) X-ray photoelectron studies on some oxides and hydroxides of cobalt, nickel, and copper. Anal Chem 47:2208-2213. https://doi.org/10.1021/ac60363a034

51. Brainard WA, Wheeler DR (1978) J Vac Sci Technol A 15:1800

52. Kurmaev EZ, Fedorenko VV, Galakhov VR, Bartkowski S, Uhlenbrock S, Neumann M et al (1996) J Supercond 9:97-100

53. Gouin X, Grange P, Bois L, L'Haridon P, Laurent Y (1995) J Alloys Compd 224:22-28

54. Jiang W-J, Niu S, Tang T et al (2017) Crystallinity-modulated electrocatalytic activity of a Nickel(II) borate thin layer on Ni3B for efficient water oxidation. Angew Chem Int Ed 56:6572-6577. https://doi.org/10.1002/anie.201703183
55. Teng X, Guo L, Ji L et al (2019) Self-growing NiFe-based hybrid nanosheet arrays on Ni nanowires for overall water splitting. ACS Appl Energy Mater 2:5465-5471. https://doi.org/10.1021/acsaem. 9b00584

56. Gupta S, Jadhav H, Sinha S et al (2019) Cobalt-boride nanostructured thin films with high performance and stability for alkaline water oxidation. ACS Sustain Chem Eng. https://doi.org/10.1021/ acssuschemeng.9b03995

Publisher's Note Springer Nature remains neutral with regard to jurisdictional claims in published maps and institutional affiliations.

\section{Authors and Affiliations}

\section{Y. Popat ${ }^{1} \cdot$ M. Orlandi ${ }^{1} \cdot$ S. Gupta ${ }^{2} \cdot$ N. Bazzanella ${ }^{1} \cdot$ S. Pillai ${ }^{3} \cdot$ M. K. Patel $^{2} \cdot$ A. Miotello $^{1} \cdot$ N. Patel $^{4}$}

\section{Y. Popat}

yakshj@yahoo.co.in; yakshjyotindra.popat@alumni.unitn.it

1 Department of Physics, Università degli Studi di Trento, 38123 Povo, Trento, Italy

2 School of Engineering, University of Liverpool, Liverpool L69 3GH, UK
3 Materials Science and Technology Division, CSIR-National Institute for Interdisciplinary Science and Technology, Thiruvananthapuram 695019, India

4 Department of Physics and Electronics, Christ University, Bengaluru, Karnataka 560029, India 